\title{
Identification of atrial septal defects by cross-sectional contrast echocardiography
}

\author{
P D V BOURDILLON, R A FOALE, A F RICKARDS \\ From the National Heart Hospital, Westmoreland Street; and \\ The Cardiothoracic Institute, Beaumont Street, London
}

SUMMARY Cross-sectional echocardiography, combined with injections of contrast into peripheral arm veins, has been used to study 15 patients with atrial septal defects and 10 patients with an intact interatrial septum. Of 11 patients with ostium secundum or sinus venosus atrial septal defects and left-to-right shunts a defect could be visualised in all, and in eight some degree of transfer of contrast from right atrium to left atrium was seen. In three of four patients with a dominant right-to-left shunt a defect was seen and in all there was free transfer of contrast from right atrium to left atrium. Though there may be variable loss of echoes in the septal image in patients with an intact interatrial septum, in general no fixed defect is seen and there is no transfer of contrast from right atrium to left atrium. This is a potentially valuable technique in the assessment of patients in whom an atrial septal defect is suspected.

In the investigation of atrial septal defects by $M$ mode echocardiography, the features described have included dilatation of the right ventricle, reversed motion of the interventricular septum, and increased amplitude of opening motion of the tricuspid valve relative to the mitral valve. ${ }^{1-3}$ These criteria have been found to be lacking in sensitivity and specificity by some workers. ${ }^{4}$ In general it is not possible to visualise the interatrial septum directly by $M$-mode echocardiography though this can be done using cross-sectional echocardiography. ${ }^{5-9}$ With the additional use of injections of contrast the presence or absence of interatrial shunts can also be assessed. ${ }^{9-12}$ The purpose of this study was to evaluate the use of cross-sectional echocardiography combined with contrast injections into peripheral arm veins in the investigation of patients with atrial septal defects.

\section{Patients and methods}

Fifteen patients with atrial septal defects, age range 6 to 53 years, were studied. Eleven patients had a dominant left-to-right shunt shown by estimation of oxygen saturations at cardiac catheterisation, with no detectable right-to-left shunt. Nine of these patients had an ostium secundum atrial septal defect, one a sinus venosus atrial septal defect, and Received for publication 22 January 1980 one had Lutembacher's syndrome-an ostium secundum atrial septal defect and mitral stenosis. Four patients who were clinically cyanosed had a dominant right-to-left shunt, two with total anomalous pulmonary venous drainage, one with a secundum atrial septal defect and pulmonary hypertension at systemic level (Eisenmenger syndrome), and one with complex congenital heart disease including dextrocardia and double outlet

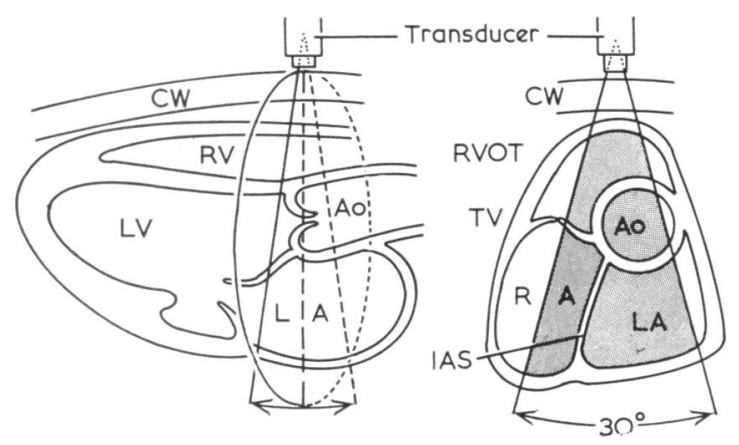

Fig. 1 Diagram illustrating (left) the long axis of the heart and the plane of the ultrasound scan when the short axis view (right) is used.

Ao, aorta; $C W$, chest wall; IAS, interatrial septum; $L A$, left atrium; $R A$, right atrium; $R V O T$, right ventricular outflow tract; $T V$, tricuspid valve. 
right ventricle with free mixing across an atrial septal defect. All patients except one were also investigated by cardiac catheterisation, the one exception being the patient with Eisenmenger's syndrome in whom the diagnosis was subsequently confirmed at necropsy.

The patients were studied by $\mathrm{M}$-mode and crosssectional echocardiography using a mechanical $30^{\circ}$ sector scanner with a $2 \cdot 25 \mathrm{MHz}$ transducer (Smith Kline Instrument Company). In all patients a variety of transducer positions were used to visualise the interatrial septum as well as possible.
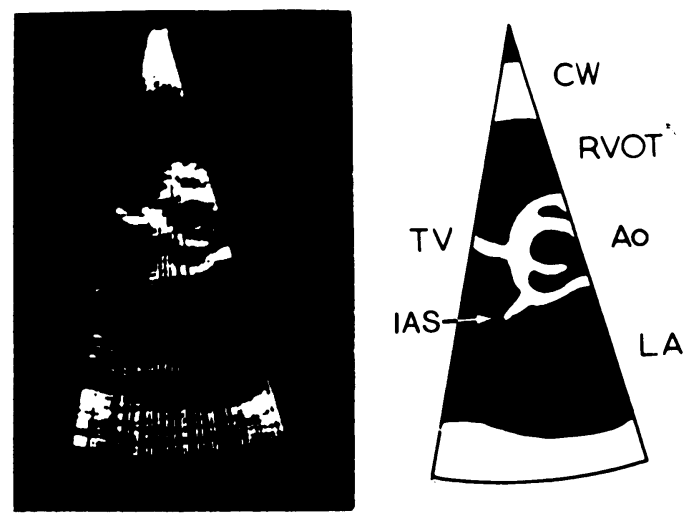

a
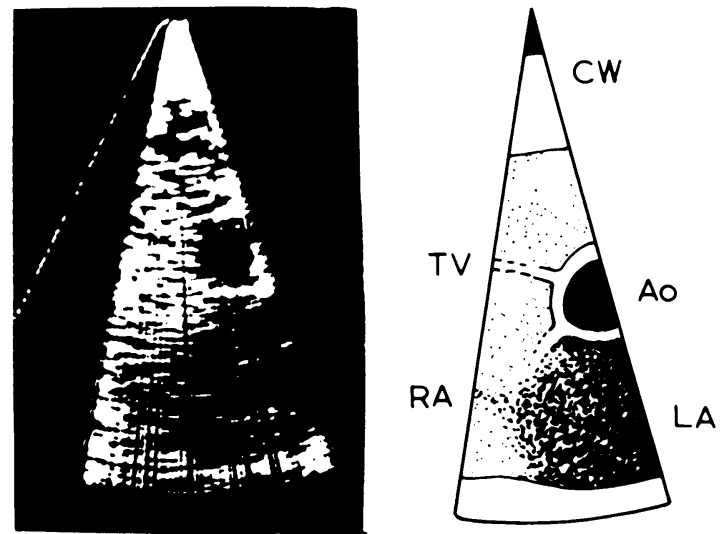

b

Fig. 2 Atrial septal defect (ostium secundum) and left-to-right shunt : single frames (left) and diagrams (right); (a) before, and (b) after contrast injections. The interatrial septum (IAS) is shown to be defective of echoes posteriorly, and after injection of contrast into a peripheral arm vein contrast echoes are seen in the left atrium ( $L A$ ) in addition to filling the right atrium (RA) and the right ventricular outflow tract (RVOT). Ao, aorta; $C W$, chest wall; $T V$, tricuspid valve.
These included apical four-chamber and subxiphoid views in addition to the parasternal short axis view in the plane of the aortic root (Fig. 1), with the transducer held in the third or fourth interspace at the left sternal edge. In some patients better visualisation of the interatrial septal defect was obtained with a modified short axis view, the transducer being held more laterally between the apex and the left sternal edge. Indocyanine green dye, 5 per cent dextrose, or normal saline were injected as contrast into a peripheral arm vein. In addition to the 15 patients with atrial septal defects, 10 patients with an intact interatrial septum were also studied using peripheral contrast injections.

The images were initially viewed on an oscilloscope and stored on magnetic tape. They were subsequently recorded on $35 \mathrm{~mm}$ cine film using a cine camera synchronised with the sweep of the scanning ultrasound beam to produce cine film at 15 frames per second.

\section{Results}

In all patients the interatrial septum was adequately visualised using the parasternal short axis view or a modified parasternal view with the transducer held more laterally. Good visualisation was achieved in four patients with the apical four-chamber view and in one child, aged 9, with both subxiphoid and apical views. In the 11 patients with an atrial septal defect and a left-to-right shunt a defect was seen in the septal image (Fig. 2 and 3). In three of the patients with a right-to-left shunt a similar appearance was seen (Fig. 4), but in the patient with complex congenital heart disease the septal defect was not consistently seen. The appearance of the interatrial septum in patients with a septal defect differs from that in patients with an intact septum in that, though there is often variable loss of echoes in the image of an intact septum as the septum moves across the plane of ultrasound during the cardiac cycle, there is generally no position of the ultrasound plane in which a fixed defect is seen. In patients with an intact interatrial septum an apparently fixed defect may be seen with certain transducer positions but this appearance is qualitatively different from that seen in most patients with an atrial septal defect in whom the upper edge of the defect is well defined (Fig. 3) and moves with a fixed relation to the aortic root during the cardiac cycle.

After injection of contrast into a peripheral arm vein in patients with an intact interatrial septum, contrast was seen initially in the right atrium and subsequently in the right ventricular outflow tract (Fig. 5). No contrast was seen in the left atrium and 

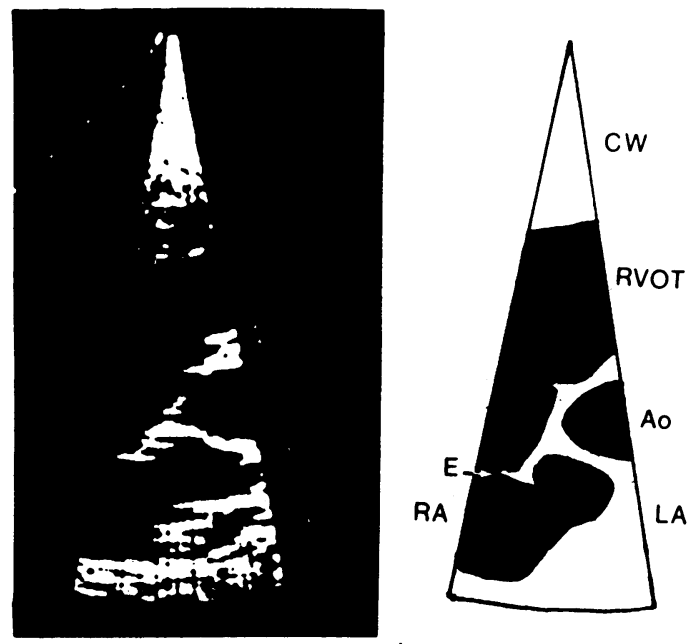

a
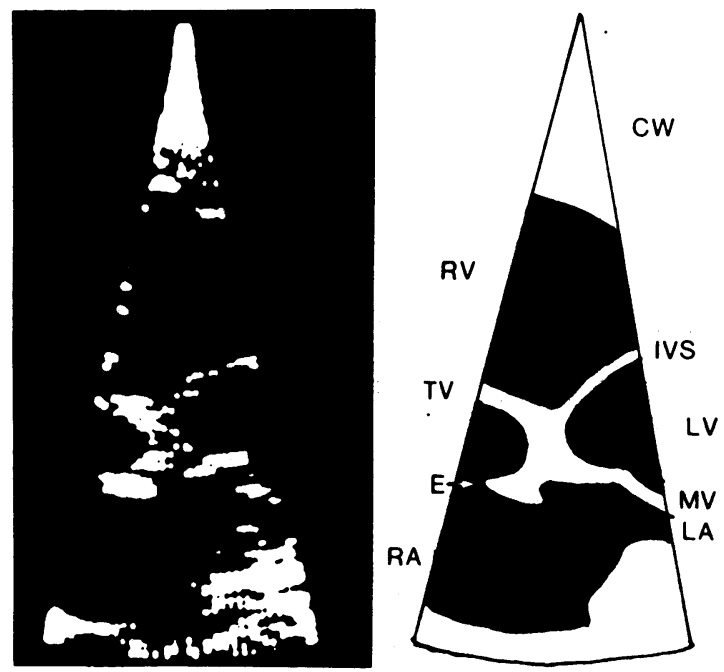

b

the interatrial septum was outlined by the contrast in the right atrium. In the patients with a dominant right-to-left shunt free transfer of contrast from right atrium to left atrium was seen (Fig. 4), with contrast subsequently appearing in the aortic root. In eight of the patients with a dominant left-toright shunt some degree of transfer of contrast
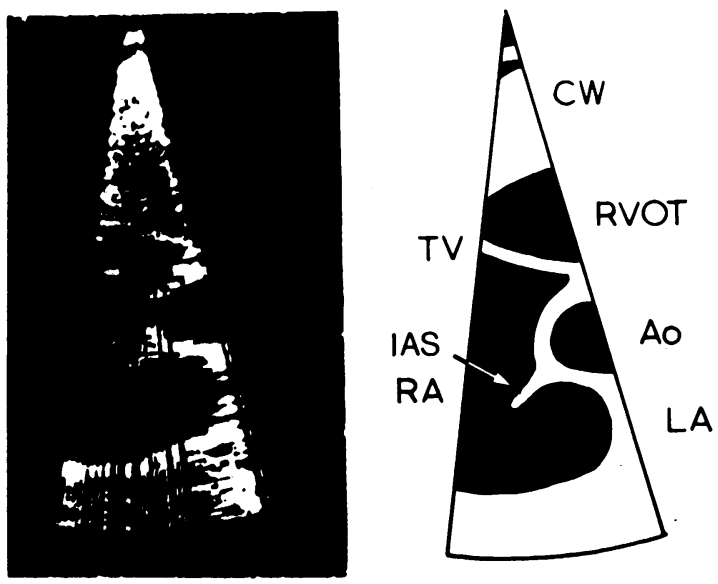

2
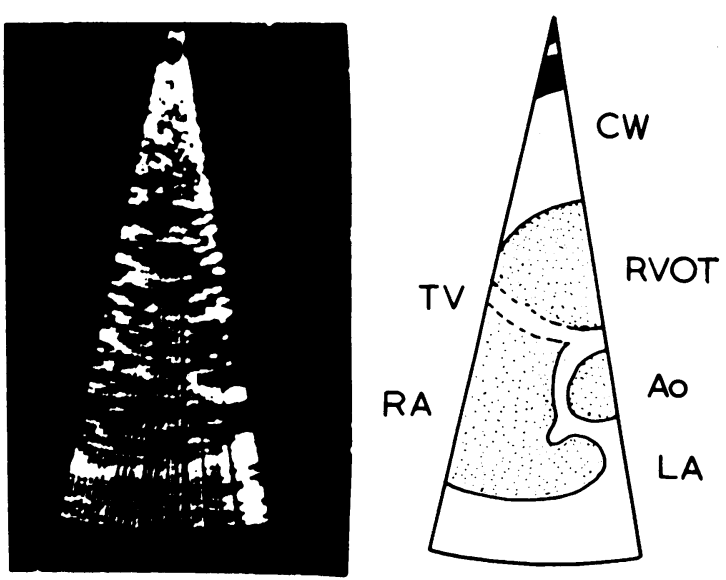

Fig. 3 Atrial septal defect (ostium secundum) and left-to-right shunt: single frames (left) and diagrams (right); (a) parasternal short axis view showing a well-defined upper edge (E) to the atrial septal defect, and (b) modified parasternal view in the same patient, with the transducer held more laterally between the left sternal edge and the apex. The well-defined edge (E) is clearly seen. The mitral valve (MV) and the upper part of the interventricular septum (IVS) at its junction with the anterior wall of the aortic root are also seen in this view. Ao, aortic root; CW, chest wall; $L A$, left atrium; $L V$, left ventricle; $R V$, right ventricle; $R A$, right atrium; $T V$, tricuspid valve. 
from right atrium to left atrium was seen (Fig. 2). The three patients with a left-to-right shunt in whom contrast was not seen to enter the left atrium were the patient with Lutembacher's syndrome in whom there was a mean pressure difference of $5 \mathrm{mmHg}$ between left atrium and right atrium caused by the presence of mitral stenosis in addition to the secundum atrial septal defect; one patient with a secundum atrial septal defect and a very small left-to-right shunt with a pulmonary to systemic flow ratio of $1 \cdot 3: 1$; and a patient in whom the injection of contrast failed to opacify the right atrium adequately.

Attention was paid in all patients to the presence or absence of a negative contrast effect within the right atrium caused by left-to-right shunting of blood across the defect. This could be seen with confidence in only one patient. In this patient the positive transfer of contrast from right atrium to left atrium was particularly obvious.

\section{Discussion}

The interatrial septum can be visualised using cross-sectional echocardiography and in patients with an atrial septal defect there is loss of echoes in the posterior part of the septal image. As other workers have found, ${ }^{5-912}$ the appearance of the defect in the septal image can be difficult to distinguish from the variable loss of echoes that is seen in patients with an intact interatrial septum. We have found that in most patients with an atrial septal defect the appearance of the edge of the anterior part of the septal image differs qualitatively from that seen in normal patients in that the echoes from the edge are more intense and that this edge moves with a constant relation to the aortic root during the cardiac cycle. Though the appearance of an edge can be produced in patients with an intact interatrial septum, the position of this edge tends to vary more in relation to the aortic root during the cardiac cycle and with different planes of ultrasound.

The short axis view in the plane of the aortic root, modified in some cases by holding the transducer more laterally between the left sternal edge and the apex, was found to be the most satisfactory view for visualisation of the interatrial septum in this group of patients. Other workers have found apical or subxiphoid views more useful for the identification of atrial septal defects. ${ }^{6} 7$ This difference may be partly explained by the age of our patients, all but two of whom were adults, since it is often not possible in adults to obtain these views adequately.

We did not include patients with ostium primum atrial septal defects in this study since the appearance of the interatrial septum and atrioventricular valves differs from the normal appearance in a number of important respects ${ }^{5}$ which make this group of patients more readily distinguishable from patients with ostium secundum or sinus
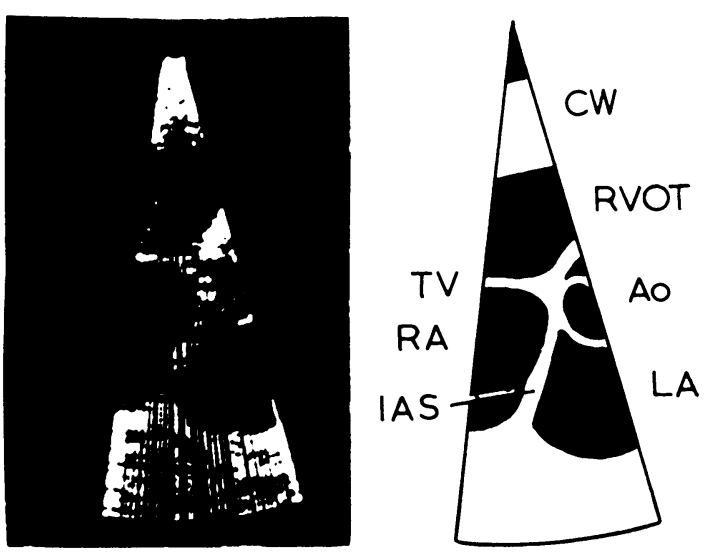

a
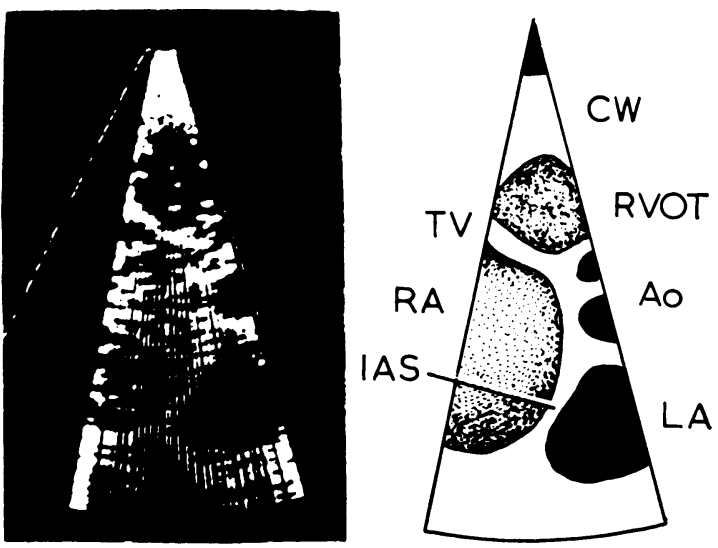

b

Fig. 5 Intact interatrial septum: single frames (left) and diagrams (right); (a) before, and (b) after contrast injections. The intact interatrial septum (IAS) separates the right atrium ( $R A$ ) from the left atrium $(L A)$, and after injection of contrast into a peripheral arm vein contrast echoes fill the $R A$ and right ventricular outflow tract (RVOT), outlining the IAS. In this patient the RA and RVOT are enlarged because of a large left-to-right shunt resulting from a communication between the $L A$ and coronary sinus, with a persistent left superior vena cava. Ao, aorta; $C W$, chest wall; $T V$, tricuspid valve. 
venosus defects and patients with intact interatrial septa.

In an individual patient examined by an experienced operator the appearance of the septal image can strongly suggest the presence of an ostium secundum atrial septal defect. This however is essentially a negative and, to some extent, a subjective finding. The transfer of contrast echoes from right atrium to left atrium is a positive feature which confirms the presence of a defect. The results we have obtained using this technique are similar to those of other workers ${ }^{9-11}$ in that most patients with an atrial septal defect and a left-to-right shunt show some degree of transfer of contrast echoes from right atrium to left atrium after injection into a peripheral arm vein.

We have not been able to confirm the findings of Weyman et al. ${ }^{12}$ who found that the appearance of a negative contrast effect to the right of the interatrial septum was a more useful indicator of a left-to-right shunt than either the appearance of the defect itself or the positive transfer of contrast echoes from right atrium to left atrium. This negative contrast effect is more difficult to assess objectively than the appearance of contrast echoes in the unopacified left atrium, and on theoretical grounds it may be difficult to distinguish from other negative contrast effects caused by blood entering the right atrium from the coronary sinus and venae cavae.

The technique of cross-sectional echocardiography combined with contrast injections may also be useful when no fixed defect can be seen in the septal image and no transfer of contrast from right to left atrium is seen, since these negative findings indicate that the interatrial septum is intact. In one of the patients studied an atrial septal defect was strongly suspected on clinical grounds. The patient was subsequently found at cardiac catheterisation to have a persistant left superior vena cava with left atrial and coronary sinus communications, and cross-sectional contrast echocardiography helped to confirm that the interatrial septum was intact (Fig. 5), in addition to demonstrating the enlarged coronary sinus and left atrial communication. ${ }^{13}$

\section{Conclusions}

Cross-sectional echocardiography is a valuable technique in the assessment of patients in whom an atrial septal defect is suspected. A relatively specific appearance of the interatrial septum is observed in patients with atrial septal defects and injection of contrast into a peripheral arm vein helps to confirm the presence or absence of a defect.

\section{References}

1 Diamond MA, Dillon JC, Haine CL, Chang S, Feigenbaum $H$. Echocardiographic features of atrial septal clefect. Circulation 1971; 43: 129-35.

2 McCann WD, Harbold NB Jr, Giuliani ER. The echocardiogram in right ventricular overload. $\mathcal{f} A M A$ 1972; 221 : 1243-5.

3 Radtke WE, Tajik AJ, Gau GT, Schattenberg TT, Giuliani ER, Tancredi RD. Atrial septal defect: echocardiographic observations. Studies in 120 patients. Ann Intern Med 1976; 84: 246-53.

4 Hagan AD, Francis GS, Sahn DJ, Karliner JS, Friedman WF, O'Rourke RA. Ultrasound evaluation of systolic anterior septal motion in patients with and without right ventricular volume overload. Circulation 1974; 50: 248-54.

5 Dillon JC, Weyman AE, Feigenbaum H, Eggleton RC, Johnston K. Cross-sectional echocardiographic examination of the interatrial septum. Circulation 1977; 55: 115-20.

6 Bierman FZ, Williams RG. Subxiphoid two dimensional imaging of the atrial septum (abstract). Am $\mathcal{F}$ Cardiol 1978; 41 : 354.

7 Tajik AJ, Seward JB, Hagler DJ, Mair DD, Lie JT. Two-dimensional real-time ultrasonic imaging of the heart and great vessels: technique, image orientation, structure identification and validation. Mayo Clin Proc 1978; 53: 271-303.

8 Schapira JN, Martin RP, Fowles RE, Popp RL. Single and two-dimensional echocardiographic features of the interatrial septum in normal subjects and patients with an atrial septal defect. $A m \mathcal{F}$ Cardiol 1979; 43: 816-9.

9 Fraker TD Jr, Harris PJ, Behar VS, Kisslo JA. Detection and exclusion of interatrial shunts by twodimensional echocardiography and peripheral venous injection. Circulation 1979; 59: 379-84.

10 DeMaria AN, Bommer W, George L, Neumann A, Weinert L, Mason DT. Combined peripheral venous injection and cross-sectional echocardiography in the evaluation of cardiac disease (abstract). $A m \mathcal{F}$ Cardiol 1978; 41 : 370.

11 Kronik G, Slany J, Moesslacher H. Contrast Mmode echocardiography in diagnosis of atrial septal defect in acyanotic patients. Circulation 1979; 59: 372-8.

12 Weyman AE, Wann LS, Caldwell RL, Hurwitz RA, Dillon JC, Feigenbaum H. Negative contrast echocardiography: a new method for detecting left-toright shunts. Circulation 1979; 59: 498-505.

13 Foale RA, Bourdillon PDV, Somerville J, Rickards AF. Echocardiographic features of anomalous systemic and coronary venous return (abstract). Br Heart f 1979; 41: 381-2.

Requests for reprints to Dr A F Rickards, National Heart Hospital, Westmoreland Street, London W1M 8BA. 